Article

\title{
Optimization of Nano-Process Deposition Parameters Based on Gravitational Search Algorithm
}

\author{
Norlina Mohd Sabri ${ }^{1, *}$, Nor Diyana Md Sin ${ }^{2}$, Mazidah Puteh ${ }^{1}$ and Mohamad Rusop Mahmood ${ }^{2}$ \\ 1 Faculty of Computer and Mathematical Sciences, Universiti Teknologi MARA (Terengganu), \\ 23000 Dungun, Malaysia; mazidahputeh@tganu.uitm.edu.my \\ 2 NANO-ElecTronic Centre, Faculty of Electrical Engineering, Universiti Teknologi MARA, \\ 40450 Shah Alam, Malaysia; nordiyana86@yahoo.com (N.D.M.S.); rusop@salam.uitm.edu.my (M.R.M.) \\ * Correspondence: norli097@tganu.uitm.edu.my; Tel.: +60-019-7901417
}

Academic Editor: Laith Al-Jobouri

Received: 9 March 2016; Accepted: 31 May 2016; Published: 8 June 2016

\begin{abstract}
This research is focusing on the radio frequency (RF) magnetron sputtering process, a physical vapor deposition technique which is widely used in thin film production. This process requires the optimized combination of deposition parameters in order to obtain the desirable thin film. The conventional method in the optimization of the deposition parameters had been reported to be costly and time consuming due to its trial and error nature. Thus, gravitational search algorithm (GSA) technique had been proposed to solve this nano-process parameters optimization problem. In this research, the optimized parameter combination was expected to produce the desirable electrical and optical properties of the thin film. The performance of GSA in this research was compared with that of Particle Swarm Optimization (PSO), Genetic Algorithm (GA), Artificial Immune System (AIS) and Ant Colony Optimization (ACO). Based on the overall results, the GSA optimized parameter combination had generated the best electrical and an acceptable optical properties of thin film compared to the others. This computational experiment is expected to overcome the problem of having to conduct repetitive laboratory experiments in obtaining the most optimized parameter combination. Based on this initial experiment, the adaptation of GSA into this problem could offer a more efficient and productive way of depositing quality thin film in the fabrication process.
\end{abstract}

Keywords: gravitational search algorithm; optimization; magnetron sputtering process; deposition parameters

\section{Introduction}

The nano-process is a process which involves application of structures at nanometer scale or at the atomic scale, which lies between 1 and 100 nanometers. Industries that have applied nano-processes include aerospace, automotive, biotechnology, ceramics, chemicals, computing, defense, electronics, metals, materials, paper, plastics, renewable energy, textiles and telecommunications [1]. This research is focusing on the radio frequency (RF) magnetron sputtering process; a physical vapor deposition technique which is widely used in the thin film production. This process requires the optimized combination of deposition parameters in order to obtain the desirable thin film as the output. Thin film is a layer of material such as titanium, zinc, copper and chromium which has a scale from a nanometer to several micrometers in thickness. Thin film is used in the production of electronic devices such as semiconductor, transistor, solar cell, led and sensor [2]. A more detailed explanation on RF magnetron sputtering is discussed in the third section of this paper. The common practice in achieving the most optimized magnetron sputtering process parameters in order to obtain the desirable thin film is done by trial and error method. This conventional optimization process requires repetitions of the laboratory experiments until the desirable experimental results are obtained. This method has been reported to be 
costly and time consuming due to the repetitive laboratory experiments [3]. The repetitive laboratory works are consuming the source materials which are usually expensive and more electrical energy from the machine usage. A longer machine time is needed to achieve the desirable experimental results. This trial and error process could take weeks to complete, including the time taken for the thin film measurements process afterwards. In order to reduce the time taken and costs in the fabrication process, a computational experiment could be performed to optimize the process parameters before any actual laboratory works are done [4,5]. The computational experiment could complement the conventional method of process parameters optimization and is expected to reduce the number of laboratory experiments that have to be conducted in the fabrication process.

This research is proposing gravitational search algorithm (GSA) technique in solving the RF magnetron sputtering deposition parameters optimization problem. This algorithm has been chosen due to its acceptable performance in solving various engineering optimization problems [6-9]. Based on literatures, GSA has better exploration capability [10], has better capability to escape from local optima [10], easier to implement [11] and has the ability to solve highly nonlinear optimization problems [12]. At the moment, GSA has not yet been explored in the nano-process parameter optimization problem. Currently, only several researches have been done in the optimization of magnetron sputtering process parameters based on computational intelligence techniques. At the time of writing, Genetic Algorithm (GA) and Particle Swarm Optimization (PSO) are among the techniques that have been adapted in this area. However, only certain process parameters are involved and the parameters are different in each of the research approaches. The materials used in the previous researches are also different and the optimizations are done for different applications. More explanation on the techniques and process parameters that have been used in the similar research are slotted in the Brief Reviews section. The research in this field is still limited and is still in the early phase as computational intelligence has not been extensively and stably adapted in the nano-process parameter optimization.

In this research, the optimized parameter combination is expected to produce the desirable electrical and optical properties of the thin film. The objective of this research is to propose a better, efficient and productive technique in the sputtering process parameter optimization problem. Besides improving the conventional method, the adaptation of computational intelligence into this problem is expected to widen the capabilities of this technique into another new application domain.

\section{Problem Formulation}

The objective function for this optimization problem is adapting the desirability function by Derriger and Suich [13]. Desirability function is a statistical technique for the simultaneous optimization of several response variables or output [14]. This function is able to address the problems of having to combine multiple independent variables (input). Instead of having to optimize each of the independent variables, this function could merge them into a single value of the desirable combination of properties. There are three response types of individual desirability functions that could be transformed into a single desirability value. They are the minimization, maximization and "target is best" functions. For the minimization function, the estimated output is expected to be smaller than the upper bound, while for the maximization, the value of the estimated output is expected to be larger than the lower bound. As for "target is best" function, the estimated output is expected to achieve the particular target value. In this research, there are six deposition parameters which have to be optimized and evaluated based on their suitable desirability functions. The parameters are expected whether to be minimized, maximized or evaluated based on "target is best". In this problem, the setting values for oxygen flow rate and working pressure are expected to be minimized, while the argon flow rate and substrate temperature are to be maximized. The RF power and deposition time are evaluated based on "target is best" function. The minimization, maximization and "target is best" functions are shown in Figure 1a-c respectively. 


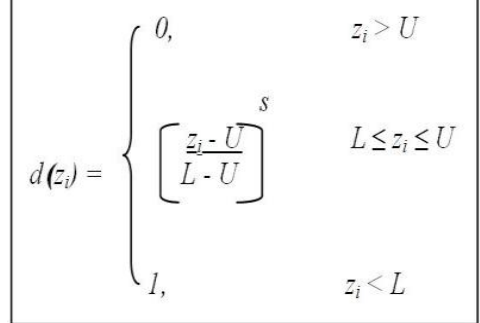

(a)

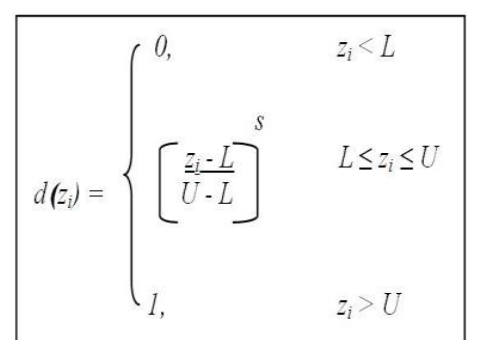

(b)

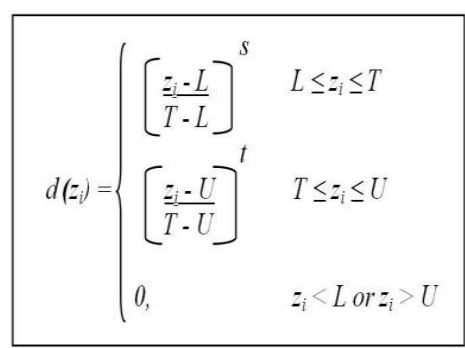

(c)

Figure 1. Desirability functions: (a) Minimization of output; (b) Maximization of output; (c) "Target is best".

Based on Figure $1, z_{i}$ is the input, $d$ is the output, $T$ is the target, $L$ is the lower bound and $U$ is the upper bound for the deposition parameters. The constant $s$ and $t$ are assigned to value " 1 " as it is expected that the desirability is increased in a linear manner. Table 1 shows the settings of target, lower bound and upper bound for each of the deposition parameters. The lower and upper boundsettings are based on capability of the RF sputtering machine, while the target settings are based on the best previous experimental result data. Different machines would have different limitations for lower and upper bounds and normally different source materials would produce different best experimental results that could be set as the targeted values.

Table 1. Settings for Desirability Functions.

\begin{tabular}{ccccc}
\hline No & Deposition Parameter & Lower Bound $(\boldsymbol{L})$ & Upper Bound $(\boldsymbol{U})$ & Target $(T)$ \\
\hline 1 & RF power (watt) & 10 & 450 & 200 \\
2 & Deposition time (min) & 1 & 240 & 60 \\
3 & Oxygen flow rate (sccm) & 0 & 100 & - \\
4 & Argon flow rate $(\mathrm{sccm})$ & 1 & 100 & - \\
5 & Substrate temperature $\left({ }^{\circ} \mathrm{C}\right)$ & 25 & 500 & - \\
6 & Working pressure (mTorr) & 1 & 50 & - \\
\hline
\end{tabular}

Each of the desirability value of the parameters, $d_{i}$ would be combined into a compound desirability value, $D$. This optimization is to maximize the $D$ value, as in Equation (1):

$$
D=\left(d_{1} \times d_{2} \times d_{3} \times d_{4} \times d_{5} \times d_{6}\right)^{1 / 6}
$$

Based on Equation (1), $d_{1}, d_{2}, d_{3}, d_{4}, d_{5}$ and $d_{6}$ represent RF power, deposition time, oxygen, argon, substrate temperature and working pressure respectively. The individual desirability values from the process parameters are to be combined to obtain the compound $\mathrm{D}$ value. In this problem, the $\mathrm{D}$ value is identified as the objective function value. The inequality constraints for each of the deposition parameters are shown in Table 2.

Table 2. Inequality constraints for deposition parameters.

\begin{tabular}{cc}
\hline No. & Constraints \\
\hline 1 & $10 \leqslant$ power $($ watt $) \leqslant 450$ \\
2 & $1 \leqslant$ time $(\min ) \leqslant 240$ \\
3 & $0 \leqslant$ oxygen $(\mathrm{sccm}) \leqslant 100$ \\
4 & $1 \leqslant$ argon $(\mathrm{sccm}) \leqslant 100$ \\
5 & $25 \leqslant$ temperature $\left({ }^{\circ} \mathrm{C}\right) \leqslant 500$ \\
6 & $1 \leqslant$ pressure $($ mTorr $) \leqslant 50$ \\
\hline
\end{tabular}




\section{Brief Reviews}

\subsection{RF Magnetron Sputtering Process}

Magnetron sputtering is a physical vapor deposition (PVD) technique which is widely applied in thin film technology. This process is used for depositing quality thin films and surface modification [15]. The process is called "sputtering" due to the atoms ejection inside the machine chamber. This is due to the bombardment of argon ions towards the target material. The transfer of kinetic energy produces atoms of target material that would fly towards the substrate to be coated. The characteristics of the thin layer formed on the substrate are depending on the deposition parameters such as power, gas flow rates, deposition time, substrate temperature and pressure. Among applications that benefited from thin film construction is electronic devices such as semiconductor, transistor, solar cell, led and sensor [2]. Figure 2 shows the illustration of the magnetron sputtering process.

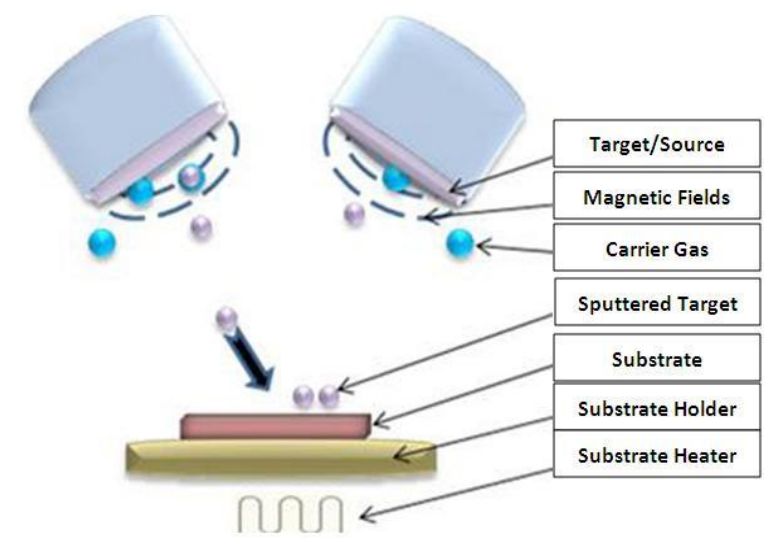

Figure 2. Magnetron sputtering process.

\subsection{Optimization of Sputtering Process Parameters Based on Computational Intelligence Techniques}

Currently, the studies on the computational methods in the RF magnetron sputtering parameter optimization problems are still limited and are at its early stage. Therefore, this review also includes other types of PVD processes such as roll-to-roll continuous sputtering process, direct current (DC) magnetron sputtering and unbalanced magnetron sputtering system. Table 3 shows the sputtering process parameters optimization based on computational intelligence techniques from the previous 5 years. The table provides information on the type of process, the applied technique, the parameters, the material used, result and the reference. The studies in this area have tested the older techniques such as Artificial Neural Network (ANN), Genetic Algorithm (GA) and Particle Swarm Optimization (PSO). In few of the studies, ANN and GA have been integrated with statistical techniques: Taguchi and Desirability function [11,14]. The optimization problems have involved different process parameters and different materials such as $\mathrm{ZrN}$, TiN and ITO. Based on Table 3, the overall results from the previous studies have proven that the computational intelligence techniques are better than the conventional approach. The results have proven that these techniques are promising and effective in solving the process parameters optimization problems. 
Table 3. Optimization of process parameters based on computational intelligence techniques.

\begin{tabular}{|c|c|c|c|c|c|}
\hline Process Type & Technique & Parameters & Material & Result & Ref. \\
\hline PVD process & $\begin{array}{c}\text { GA, } \\
\text { Taguchi }\end{array}$ & $\begin{array}{l}\text { (1) Gas } \\
\text { (2) Chamber pressure } \\
\text { (3) Power input }\end{array}$ & $\begin{array}{c}\text { Zirconium } \\
\text { nitride }(\mathrm{ZrN})\end{array}$ & $\begin{array}{l}\text { Achieve higher } \\
\text { coating performance. }\end{array}$ & [16] \\
\hline $\begin{array}{c}\text { PVD } \\
\text { Magnetron } \\
\text { Sputtering }\end{array}$ & $\mathrm{PSO}$ & $\begin{array}{l}\text { (1) Nitrogen pressure } \\
\text { (2) Argon pressure } \\
\text { (3) Turntable Speed }\end{array}$ & $\begin{array}{l}\text { Titanium nitrite } \\
\text { (TiN) }\end{array}$ & $\begin{array}{l}\text { Acceptable } \\
\text { performance }\end{array}$ & [5] \\
\hline $\begin{array}{l}\text { Unbalanced } \\
\text { magnetron } \\
\text { sputtering }\end{array}$ & GA & $\begin{array}{l}\text { (1) Nitrogen pressure } \\
\text { (2) Argon pressure } \\
\text { (3) TurntableSpeed }\end{array}$ & $\begin{array}{l}\text { Titanium Nitride } \\
\text { (TiN) }\end{array}$ & $\begin{array}{l}\text { Reduce the } \\
\text { minimum value of } \\
\text { coating layer grain } \\
\text { size feature. }\end{array}$ & [17] \\
\hline $\begin{array}{l}\text { Roll-to-roll } \\
\text { continuous } \\
\text { sputtering }\end{array}$ & $\begin{array}{l}\text { ANN, GA, } \\
\text { Taguchi, } \\
\text { desirability } \\
\text { function }\end{array}$ & $\begin{array}{l}\text { (1) Chamber pressure } \\
\text { (2) Sputtering power } \\
\text { (3) Nitrogen flow rate } \\
\text { (4) Process line speed }\end{array}$ & Not stated & $\begin{array}{l}\text { Performance is better } \\
\text { than traditional } \\
\text { approach. }\end{array}$ & [13] \\
\hline $\begin{array}{l}\text { DC magnetron } \\
\text { sputtering }\end{array}$ & ANN, GA & $\begin{array}{l}\text { (1) Thin film thickness } \\
\text { (2) Annealing } \\
\text { temperature }\end{array}$ & $\begin{array}{l}\text { Indium thin } \\
\text { oxide (ITO) and } \\
\text { Aluminium (Al) }\end{array}$ & $\begin{array}{l}\text { Results were well } \\
\text { matched with the } \\
\text { measured data. }\end{array}$ & [18] \\
\hline $\begin{array}{l}\text { RF magnetron } \\
\text { sputtering }\end{array}$ & ANN, GA & $\begin{array}{l}\text { (1) Thin film thickness } \\
\text { (2) Annealing } \\
\text { temperature }\end{array}$ & $\begin{array}{l}\text { Ga-doped zinc } \\
\text { oxide (ZnO:Ga) }\end{array}$ & $\begin{array}{l}\text { Effective method to } \\
\text { predict the desired } \\
\text { process condition. }\end{array}$ & [19] \\
\hline
\end{tabular}

\section{Proposed Methodology}

\subsection{Experimental Data}

In this research, the optimization involves randomly generated 100 agents or populations which represent the deposition parameters combinations. The ranges of the parameters to be optimized are shown in Table 4 . The material being selected is zinc oxide $(\mathrm{ZnO})$, due to its availability and popularity in the material science community [20]. In material science, $\mathrm{ZnO}$ has been extensively investigated based on the characteristics of the material itself that is able to produce good results for the production of various applications.

Table 4. Ranges of deposition parameters to be optimized.

\begin{tabular}{cc}
\hline Deposition Parameters & Ranges \\
\hline RF power (watt) & $50-500$ \\
Deposition time (min) & $15-240$ \\
Oxygen flow rate $(\mathrm{sccm})$ & $0-100$ \\
Argon flow rate $(\mathrm{sccm})$ & $1-100$ \\
Substrate temperature $\left({ }^{\circ} \mathrm{C}\right)$ & $20-500$ \\
Working pressure (mTorr) & $1-50$ \\
\hline
\end{tabular}

\subsection{GSA Optimization}

GSA is inspired by the Newtonian law of gravity and motion [21]. Each agent is represented by mass and is attracted to each other due to the gravitational force. Based on Equation (2), the active mass, $M_{a i}$, passive mass, $M_{p i}$ and inertia mass, $M_{i i}$ are equals with the current mass, $M_{i}$. The mass $M_{i}$ is calculated based on Equations (3) and (4).

$$
\begin{gathered}
M_{a i}=M_{p i}=M_{i i}=M_{i}, i=1,2, \ldots ., \mathrm{N} \\
m_{i}(t)=f i t_{i}(t)-\text { worst }(t) / \text { best }(t)-\text { worst }(t) \\
M_{i}(t)=m_{i}(t) / \Sigma_{\mathrm{j}}=1, \ldots, \mathrm{N} m_{j}(t)
\end{gathered}
$$


The algorithm controls its search accuracy based on the gravitational constant $G$. This is done by initializing Go and alpha, $\alpha$, at the beginning of the iteration, while time, $t$ is increasing. Gradually $G$ would reduce over time due to the decrease of the exponential value [22]. Equation (5) shows how $G$ is calculated at iteration $t$ :

$$
G(t)=G_{0} e^{(-\alpha t / T)}
$$

The constant gravitational force $G$, is used in the evaluation of the force, $F$, as shown in Equation (6):

$$
F_{i j}^{d}(t)=G(t)\left(M_{p i}(t) \times M_{a j}(t) / R_{i j}(t)+\varepsilon\right)\left(x_{j}^{d}(t)-x_{i}^{d}(t)\right)
$$

$F_{i j}{ }^{d}(t)$ is the force acting on agent $i$ from agent $j$ at $d^{t h}$ dimension and $t^{t h}$ iteration. $M_{a i}$ and $M_{p i}$ are the active and passive gravitational masses respectively. $R_{i j}(t)$ is the Euclidian distance between two agents $i$ and $j$ at iteration $t$, while $\varepsilon$ is a small constant. $x_{i}^{d}$ and $x_{j}^{d}$ represents the positions of the $i^{t h}$ and $j^{\text {th }}$ agents in the $d^{\text {th }}$ dimension. The force $F$ is determined in order to calculate the acceleration, $a$, as shown in Equation (7):

$$
a_{i}^{d}(t)=F_{i}^{d}(t) / M_{i i}(t)
$$

In the search space, the biggest mass will attract the smaller mass. In the end, the biggest mass would have the slowest movement and its position represents the solution. The formulas for velocity, $v$ and position, $x$ of each agent are shown by Equations (8) and (9) respectively.

$$
\begin{gathered}
v_{i}^{d}(t+1)=\operatorname{rand}_{i} \times v_{i}^{d}(t)+a_{i}^{d}(t) \\
x_{i}^{d}(t+1)=x_{i}^{d}(t)+v_{i}^{d}(t+1)
\end{gathered}
$$

The steps for implementing GSA to the process parameters optimization problem are as shown in Figure 3.

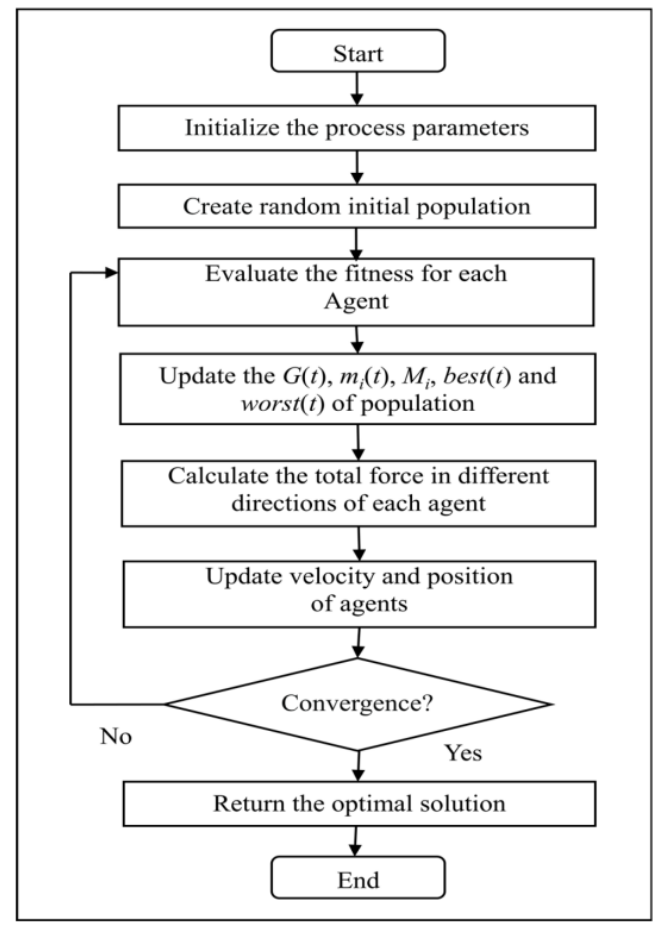

Figure 3. Steps of gravitational search algorithm (GSA) optimization.

In order to obtain the best result, the parameters of GSA have been tuned several times. The final parameter settings for GSA are as shown in Table 5. 
Table 5. Final parameter values for GSA.

\begin{tabular}{cc}
\hline Parameter & Value \\
\hline Number of agents & 100 \\
Gravitational constant, G & 10 \\
Alpha, $\alpha$ & 15 \\
Epsilon & 0.0001 \\
Iterations & 200 \\
\hline
\end{tabular}

\section{Results and Discussion}

The performance of GSA in this research was compared with that of PSO, GA, AIS and ACO. These are the older and popular algorithms which are categorized into biological (GA and AIS) and nature (ACO and PSO) inspired. They have been considered in the comparison mainly due to their previous performances in solving various engineering parameter optimization problems. PSO was selected due to its almost similar characteristics with GSA and its application in the similar type of sputtering process [23-25], while GA was selected due to its adaptation in other type of sputtering processes [26-28]. As for AIS and ACO, these algorithms have been adapted in various engineering parameter optimization problems [29-32]. All of the algorithms were executed 30 times, with their average fitness values and processing times recorded as shown in Table 6. Based on Table 6, GSA could produce the highest mean fitness value of 0.8871 , followed by GA (0.8657), PSO (0.6473), ACO (0.5553) and AIS (0.4721). As for the mean processing times, GSA has obtained the slowest execution with $5.466 \mathrm{~s}$ for the 200 iterations. This is due to the exploration characteristic of GSA which calculates the overall forces from all of the neighboring masses in the search space. This characteristic has affected the computational time of GSA. Since the computational experiment is an offline process and has to be conducted before the actual lab works, the time taken for algorithm's processing time is not of concerned for the manufacturers. However, it is important to measure the running time of the algorithm in order to observe the computational cost taken in this particular problem. The computational time is also a measure of performance of an algorithm.

Table 6. Analysis of fitness values and processing times.

\begin{tabular}{cccccc}
\hline \multirow{2}{*}{ Technique } & \multicolumn{2}{c}{ Fitness Values of Optimized Parameter Combination } & Processing Times (s) \\
\cline { 2 - 5 } & Min & Mean & Max & $\sigma$ & Mean \\
\hline GSA & 0.8871 & 0.8871 & 0.8871 & 0.0000 & 5.466 \\
PSO & 0.354 & 0.6473 & 0.847 & 0.1642 & 0.350 \\
GA & 0.8071 & 0.8657 & 0.8701 & 0.0315 & 0.726 \\
AIS & 0.0000 & 0.4721 & 0.8489 & 0.3525 & 0.484 \\
ACO & 0.5553 & 0.5553 & 0.5553 & 0.0000 & 0.634 \\
\hline
\end{tabular}

In order to validate the performance of the algorithms, the actual laboratory experiments were conducted to deposit thin films based on the parameter combinations obtained from each of the algorithm. Table 7 shows the analysis of results on the electrical and optical properties of thin films deposited based on the optimized parameter from GSA, PSO, GA, AIS and ACO. Conductivity is one of the analyses for electrical properties, which measures the electrical current that flows through a material. Meanwhile, band gap is the analysis for optical property, which measures the capability of light to carry electrical energy through the material. Band gap is also referred to as the energy difference between the top of the valence band and the bottom of the conduction band in insulators and semiconductors. 
Table 7. Actual laboratory experimental results.

\begin{tabular}{cccccc}
\hline \multirow{2}{*}{-} & \multicolumn{5}{c}{ Actual Laboratory Experiment Results } \\
\cline { 2 - 6 } & GSA & PSO & GA & AIS & ACO \\
\hline Most optimized & $(200,60,0$, & $(200,60,5$, & $(200,59,0$, & $(200,60,5$, & $(50,60,5$, \\
parameter combination & $45,500,7)$ & $45,400,7)$ & $45,485,7)$ & $45,500,7)$ & $45,200,7)$ \\
\hline Fitness value & 0.8871 & 0.847 & 0.8701 & 0.8489 & 0.5553 \\
\hline Conductivity $\left(\mathrm{Sm}^{-1}\right)$ & 13.2 & 5.46 & 7.68 & 5.78 & 0.00128 \\
\hline Optical band gap energy $(\mathrm{eV})$ & 3.28 & 3.12 & 3.24 & 3.31 & 3.24 \\
\hline
\end{tabular}

Based on Table 7, the highest conductivity is achieved by GSA with $13.2 \mathrm{Sm}^{-1}$, followed by GA with $7.68 \mathrm{Sm}^{-1}$ and AIS with $5.78 \mathrm{Sm}^{-1}$. The highest optical band gap energy is $3.31 \mathrm{eV}$, which is achieved by AIS. GSA, GA and ACO have obtained acceptable results of $3.28 \mathrm{eV}$ and $3.24 \mathrm{eV}$ respectively for the optical band gaps. Based on the overall results, the thin film that has been deposited based on GSA optimized parameter combination has generated the best electrical property and acceptable result of optical property among others. In thin film fabrication, the specific values of these electrical and optical properties are required by the manufacturers based on the end product or the electronic components they are intended for. The electronic components could be sensors, transistors, capacitors, LED, solar cells and other semiconductor devices. Based on Table 7, it could be concluded that the result of the electrical property is highly influenced by the RF power and substrate temperature parameters.

Figure 4 shows the convergence graph of GSA, PSO, GA, AIS and ACO which is based on the average fitness values over iterations. Based on Figure 4, GSA, GA and ACO have reached their optimum and have produced stable results earlier than PSO and AIS in these 200 iterations. However, GSA and GA have generated higher fitness values compared to ACO. As for PSO and AIS, these algorithms require more time to search for the best solutions in this particular problem. This can be seen by the fluctuations of fitness values before they finally reached the optimum values. Based on literatures, GSA could generate better and faster result compared to PSO and GA [22,27]. In GSA, the heavier masses create slower motions of agents in the search space, which could lead to a more precise local search. These bigger masses cause higher attractions of agents which contribute to faster searching for the best result [21]. This could be seen in Figure 4, as GSA is able to reach higher fitness value and has demonstrated a faster search for the best result compared to other algorithms.

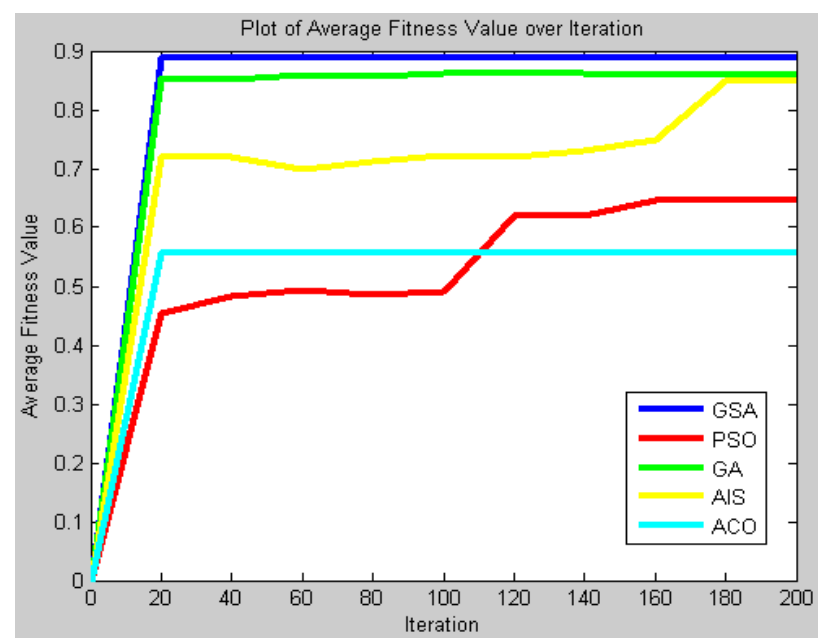

Figure 4. Plot of average fitness value over iterations. 


\section{Conclusions}

This research has adapted computational intelligence in the parameter optimization problem of RF magnetron sputtering process. The adaptation of computational intelligence is expected to improvise the conventional method of trial and error practice in the parameter optimization problem. In this research, GSA has been proposed to solve the problem due to its acceptable performance in solving various engineering optimization problems. In this research, compared to PSO, GA, AIS and ACO, GSA is able to generate better fitness value of the process parameter combination. Based on the analysis of results from the characterization of the thin films, GSA has been able to propose the optimized parameter combination in order to produce the best electrical property and an acceptable optical property. This computational experiment is expected to overcome the problem of having to conduct repetitive laboratory experiments in order to obtain the most optimized parameter combination for the thin film deposition. From the manufacturer's perspective, the ability to optimize the process parameters before the machine usage would save a lot of researchers' time, the product's material, machine's maintenance costs and could reduce rejected output results. Thus, the adaptation of GSA into this problem could offer a more efficient and productive way of depositing quality thin film in the fabrication process. Future work could test GSA with diverse sets of data to test its robustness and accuracy. Enhancement on the algorithm's original concept is also encouraged in order to improve its execution time.

Acknowledgments: The authors would like to acknowledge the supports given by Universiti Teknologi MARA (Terengganu) and NANO-ElecTronic Centre for the continuous commitments given towards the completion of this research. Special gratitude also goes to the Ministry of Education Malaysia for the sponsorship granted to the main author.

Author Contributions: Norlina Mohd Sabri, Mazidah Puteh and Mohamad Rusop Mahmood produced the ideas and designed the experiments; Norlina Mohd Sabri performed the computational experiments, while Nor Diyana Md Sin conducted the laboratory experiments and measurements; Norlina Mohd Sabri and Nor Diyana Md Sin analyzed the data; Norlina Mohd Sabri wrote the paper. All authors have approved the final manuscript.

Conflicts of Interest: The authors declare no conflict of interest.

\section{Abbreviations}

The following abbreviations are used in this manuscript:

$\begin{array}{ll}\text { GSA } & \text { Gravitational Search Algorithm } \\ \text { GA } & \text { Genetic Algorithm } \\ \text { PSO } & \text { Particle Swarm Optimization } \\ \text { ACO } & \text { Ant Colony Optimization } \\ \text { AIS } & \text { Artificial Immune System } \\ \text { AFSA } & \text { Artificial Fish Swarm Algorithm }\end{array}$

\section{References}

1. Bhat, J.S. Concerns of New Technology Based Industries-The Case of Nanotechnology. Technovation 2003, 25, 457-462. [CrossRef]

2. Fernandez, S.; Naranjo, F.B. Optimization of Aluminum-doped Zinc Oxide Films Deposited at Low Temperature by Radio-Frequency Sputtering on Flexible Substrates for Solar Cell Applications. Sol. Energy Mater. Sol. Cells 2010, 94, 157-163. [CrossRef]

3. Ho, W.; Tsai, J.; Hsu, G. Process Parameters Optimization: A Design Study for TiO Thin Film of Vacuum Sputtering Process. IEEE Trans. Autom. Sci. Eng. 2010, 7, 143-146. [CrossRef]

4. Norlina, M.S.; Mazidah, P.; Sin, N.D.M.; Rusop, M. Computational Intelligence Technique in Optimization of Nano-process Deposition Parameters. In Proceedings of the 2015 7th Computer Science and Electronic Engineering Conference, Colchester, UK, 24-25 September 2015.

5. Ath, M.U.; Jarrah, I.; Syukor, A.; Jaya, M.; Asyadi, M. Intelligence integration of particle swarm optimization and physical vapour deposition for tin grain size coating process parameters. J. Theor. Appl. Inf. Technol. 2016, 84, 355-369. 
6. Shams, M.; Rashedi, E.; Hakimi, A. Clustered-gravitational search algorithm and its application in parameter optimization of a low noise amplifier. Appl. Math. Comput. 2015, 258, 436-453. [CrossRef]

7. De Moura Oliveira, P.B.; Solteiro Pires, E.J.; Novais, P. Design of Posicast PID control systems using a gravitational search algorithm. Neurocomputing 2015, 167, 18-23. [CrossRef]

8. Saiful, M.; Aziz, I.; Wahyudi, S.; Sudin, S.; Abdul, N.; Faramarzi, M. Gravitational Search Algorithm Optimization for PID Controller Tuning in Waste-water Treatment Process. J. Teknol. 2015, 73, 103-109. [CrossRef]

9. Islam, S.M. Gravitational Search Algorithm Applied to Optimal Power Flow Problem. Int. J. Emerg. Res. Manag. Technol. 2015, 4, 120-127.

10. Sarafrazi, S.; Nezamabadi-pour, H. Facing the classification of binary problems with a GSA-SVM hybrid system. Math. Comput. Model. 2013, 57, 270-278. [CrossRef]

11. Beheshti, Z.; Mariyam, S.; Shamsuddin, H. A Review of Population-based Meta-Heuristic Algorithm. Int. J. Adv. Soft Comput. 2013, 5, 1-35.

12. Khadanga, R.K.; Panda, S. Gravitational search algorithm for Unified Power Flow Controller based damping controller design. In Proceedings of the International Conference on Energy, Automation and Signal, Bhubaneswar, India, 28-30 December 2011.

13. Lin, H.-C.; Su, C.-T.; Wang, C.-C.; Chang, B.-H.; Juang, R.-C. Parameter Optimization of Continuous Sputtering Process based on Taguchi Methods, Neural Networks, Desirability Function and Genetic Algorithms. Expert Syst. Appl. 2012, 39, 12918-12925. [CrossRef]

14. Derringer, G.; Suich, R. Simultaneous Optimization of Several Response Variables. J. Qual. Technol. 1980, 12, 2-7.

15. Yang, P.; Ren, C.S.; Wang, D.Z.; Qi, X.L.; Guo, S.H.; Ma, T.C. Influence of Additional Magnetic Field on Plasma Parameters in Magnetron Sputtering. Vacuum 2009, 83, 1376-1381. [CrossRef]

16. Sivapragash, M.; Kumaradhas, P.; Retnam, B.S.J.; Joseph, X.F.; Pillai, U.T.S. Taguchi based genetic approach for optimizing the PVD process parameter for coating ZrN on AZ91D magnesium alloy. Mater. Des. 2016, 90, 713-722. [CrossRef]

17. Jarrah, M.I.; Jaya, A.S.M.; Muhamad, M.R.; Rahman, M.N.A.; Basari, A.S. Modeling and Optimization of Physical Vapour Deposition Coating Process Parameters For TiN Grain Size Using Combined Genetic Algorithms With Response Surface Methodology. J. Theor. Appl. Inf. Technol. 2015, 77, 235-253.

18. Cho, E.N.; Moon, P.; Kim, C.E.; Yun, I. Modeling and optimization of ITO/Al/ITO multilayer films characteristics using neural network and genetic algorithm. Expert Syst. Appl. 2012, 39, 8885-8889. [CrossRef]

19. Kim, C.E.; Moon, P.; Yun, I.; Kim, S.; Myoung, J.-M.; Jang, H.W.; Bang, J. Process estimation and optimized recipes of $\mathrm{ZnO}: \mathrm{Ga}$ thin film characteristics for transparent electrode applications. Expert Syst. Appl. 2011, 38, 2823-2827. [CrossRef]

20. Veriansyah, B.; Kim, J.-D.; Min, B.K.; Shin, Y.H.; Lee, Y.-W.; Kim, J. Continuous Synthesis of Surface-Modified Zinc Oxide Nanoparticles in Supercritical Methanol. J. Supercrit. Fluids 2010, 52, 76-83. [CrossRef]

21. Rashedi, E.; Nezamabadi-pour, H.; Saryazdi, S. GSA: A Gravitational Search Algorithm. Inf. Sci. 2009, 179, 2232-2248. [CrossRef]

22. Sabri, N.M.; Puteh, M.; Mahmood, M.R. A Review of Gravitational Search Algorithm. Int. J. Adv. Soft Comput. Appl. 2013, 5, 1-39.

23. Mirjalili, S.; Hashim, S.Z.M.; Moradian Sardroudi, H. Training feedforward neural networks using hybrid particle swarm optimization and gravitational search algorithm. Appl. Math. Comput. 2012, 218, 11125-11137. [CrossRef]

24. Shrivastri, S.; Deshmukh, R. Data Classification Particle Swarm Optimization and Gravitational Search Algorithm. Int. J. Innov. Res. Sci. Eng. Technol. 2014, 3, 9734-9741.

25. Davarynejad, M.; Van Den Berg, J.; Rezaei, J. Evaluating center-seeking and initialization bias: The case of particle swarm and gravitational search algorithms. Inf. Sci. 2014, 278, 802-821. [CrossRef]

26. Kim, B.; Lee, S.; Min, C.; Kim, T. Optimization of transmittance characteristic of indium tin oxide film using neural networks. Met. Mater. Int. 2010, 16, 793-797. [CrossRef]

27. Yeh, C.-W.; Wu, K.-R. Neural network-based system for optimizing process parameters of semiconductor compounds. In Proceedings of the 2nd IEEE International Conference on Information Management and Engineering, Chengdu, China, 16-18 April 2010.

28. Tsai, J.-T.; Ho, W.-H.; Hsu, G.-M.; Liu, T.-K.; Chou, J.-H. Optimal Process Design Using Soft Computing Approaches. In Proceedings of the SICE Annual Conference 2008, Tokyo, Japan, 20-22 August 2008. 
29. Braun, C.E.; Chiwiacowsky, L.D.; Arthur, T.G. Variations of Ant Colony Optimization for the solution of the structural damage identification problem. Procedia Comput. Sci. 2015, 51, 875-884. [CrossRef]

30. Zhang, X.; Chen, W.; Wang, B.; Chen, X. Intelligent fault diagnosis of rotating machinery using support vector machine with ant colony algorithm for synchronous feature selection and parameter optimization. Neurocomputing 2015, 167, 260-279. [CrossRef]

31. Li, Z.; Li, J.; He, C.; Tang, C.; Zhou, J. RFID reader-to-reader collision avoidance model with multiple-density tag distribution solved by artificial immune network optimization. Appl. Soft Comput. 2015, 30, 249-264. [CrossRef]

32. Souza, S.S.F.; Romero, R.; Franco, J.F. Artificial immune networks Copt-aiNet and Opt-aiNet applied to the reconfiguration problem of radial electrical distribution systems. Electr. Power Syst. Res. 2015, 119, 304-312. [CrossRef]

(C) 2016 by the authors; licensee MDPI, Basel, Switzerland. This article is an open access article distributed under the terms and conditions of the Creative Commons Attribution (CC-BY) license (http://creativecommons.org/licenses/by/4.0/). 